\title{
Affect, Responsibility, and How Modes of Engagement Shape the Experience of Videogames
}

\section{Kevin Veale}

\section{ABSTRACT}

The experience of videogames is distinct from other forms of mediated storytelling because the person playing the game can come to feel responsible for events and characters within a fictional world due to dynamics within what Brendan Keogh calls the 'messy, hybrid assemblage' of videogame play:

Games function through modes of engagement where people need to make decisions and take actions in order to proceed through a hybrid text, in a context that the player is affectively invested in, and which is personally relevant to both the player and their situation. A perception of responsibility grows out of that agency, since the player's decisions have a meaningful impact on a world and characters that they already invested in treating as if they were real.

\section{Keywords}

Affect, cathexis, ergodic literature, modes of engagement, responsibility, structural incoherence, world-of-concern

\section{INTRODUCTION}

Turning the pages of a book isn't neutral to our experience of the story it tells - something that the novel House of Leaves (Danielewski 2000) uses to manipulate us by reducing the words on each page to single figures during tense sequences so that we physically turn the 
pages faster and faster as we read. Simply knowing how far through a book we are changes how we anticipate what will happen next in the story. For cinema, our structural inability to engage with the text in the context of a movie theatre is one of the defining features of the form: we can be on the edge of our seats with anticipation, but cannot do anything to intervene but look away.

What makes the experience of videogames ${ }^{1}$ distinctive from other forms of storytelling media is that we as players can come to feel responsible for what happens within the narrative world of the game - yet without being delusional and losing our grip on the fictional nature of what we're dealing with (Veale 2012a, p. 36-37, p. 69-70). Our affective responses are shaped by the modes of engagement required of us as we negotiate game texts: players become invested in the outcomes of the decisions required to engage with the game, and thus feel responsible for the consequences of their actions within that context.

The very concept of treating games as fictional texts, and comparing their experiences of storytelling to other mediated forms of fiction, is not neutral and grows out of a particular critical context. The core of the historical debate was whether videogames should best be understood along formalist lines as games in a category by themselves, or whether they could safely be considered alongside other forms of media more traditionally associated with narrative storytelling. James Wilson presents a comprehensive exploration of the discussion's critical history in Gameplay and the Aesthetics of Intimacy (Wilson 2007, p. 185-265). I join other recent critics in suggesting that videogames are best understood as experientially distinct hybrids between people, software and technology (Hayles 1999; Veale 2005; Giddings 2007; Keogh 2010; Veale 2012a; Keogh 2014). The process of negotiation within the hybrid underlies what makes games a distinctive form of mediated storytelling (Murray 1998; Jenkins 2004), because the hybrid has a decentralized agency and capacity to act within the space of the game. My own work seeks to understand the dynamics that make playing videogames distinctive from engaging with other media forms, and uses affect as a critical 
lens to study for what sets the experience apart (Veale 2010; Veale 2012a; Veale 2012b).

The role affect plays in relation to videogames and other storytelling media is something other scholars are also engaging with: Ian Shaw and Barney Warf explore the "connections between game spaces as representations and game spaces as constellations of affects," (Shaw and Warf 2009, 1333), and suggest that one of the goals of game design has always been to manipulate the affective impact on players. James Ash develops the line of enquiry by using a Deleuzian perspective on affect, initially to explore how game designers shape the experience of play in order to create desirable experiences for the people playing the game (Ash 2010), then by exploring 'retentional economies' of human and technological memory that can be used to modulate affect (Ash 2012), before investigating how videogames create 'intense spaces' designed to captivate their subjects (Ash 2013).

In this article, I argue that a perception of responsibility on the part of the person playing a game is a natural consequence of dynamics within the 'messy, hybrid assemblage' that Brendan Keogh uses to describe the experience of game play. Such a perception of responsibility is one of the elements that shapes and distinguishes the experience of playing a game from engaging with other forms of mediated storytelling.

To unpack the dynamics which make a perception of responsibility in playing games possible, I will explore the critical background to analysing affect. Next, I link affect to an attributional theory of motivation put forward by Bernard Weiner that relates thoughts and emotions to behaviour and social conduct, and which explicitly links responsibility to choice and agency. I then examine why and how the textual substrate common to videogames produces a mode of engagement that contributes to players feeling responsible for events and characters within the world of the game, and relate that responsibility back to Weiner's theories. Lastly, I consider a series of case studies in order to illustrate why the modes of engagement 
that lead to a perception of affective responsibility are central to what makes the experience of playing videogames distinctive from other forms of storytelling media.

The core theoretical contribution of this article is to provide a framework for close analysis that is open to both the 'slipperiness' of affect (Kavka 2008, 30-31) and the 'messiness' of the videogame hybrid (Keogh 2014). The analytical framework I present here explores the modes of engagement common to the hybrid of videogame play, and how these modes of engagement result in affectively distinct experiences.

\section{FRAMING AFFECTIVE RESPONSIBILITY}

In order to establish how we can apply affect analytically to the experience of fiction, we first need to explore the difficulties of doing so, and how that difficulty relates to its function and context. One of the central issues faced when dealing with affect is that it hides2 behind our emotions, which are easier to consciously identify and name: when someone recognises that they3 'feel sad,' they are finding a cognitive label for an underlying affective tone (Massumi 2002, 31-32; Veale 2012a, 41). Another distinction is that emotions are discrete, whereas affect is best understood as a continuous process flowing in the background (Massumi 2002, 217) that can contain seemingly contradictory elements blurring together. As a result, Misha Kavka frames affect as “...potential emotions - emotions that have not yet been perceived as such and thus constitute a 'primordial soup' of feeling” (Kavka 2008, x).

Affect functions within an "economy of cathexis” (Grossberg 1997, 158) - cathexis meaning the investment of mental or emotional energy in a person, object, or idea. Any given person has multiple planes of affective investment operating at the same time, all of which are heavily contextual. If we take music as an example, a person could be engaging with and investing themselves in the music itself at the same time as that music informs their personal identity; that person is also simultaneously aware of the external perception of that identity, 
viewed through the lens of the musical subculture it is framed through (Veale 2012a, 43).

A useful toolset for understanding how and why affective investment is so tied to context comes from Paddy Scannell and Lars Nyre, originally from the context of studying how people watch television. In What Happens When I Turn On The TV Set? Lars Nyre discusses an unpublished lecture given by Paddy Scannell, in which Scannell analysed the act of turning on a television set. Scannell argues that part of what makes television ubiquitous - regardless of whether or not a physical television set is 'on' in the vicinity - is the distinction between 'objective space' and the 'space humans are engaged in' that he defines as a Heideggerian world-of-concern (Nyre 2007, 26). The difference between an 'objective' space and a 'world-of-concern' is that an objective space is everything present within an environment, such as all of the furniture and fittings within a lecture theatre. In comparison, since a world-of-concern is grounded in the contextual relevance of the people involved and their situation, in the context of a lecture it would include the lecturer, the students and the subject at hand - but the majority of the room fittings are not included because they are irrelevant. When you4 have been watching a horror movie at night, your house and furniture aren't innately relevant to your worldof-concern - but can become so afterward, when every creak and shadow pick up the context and affective tenor of the film.

Affect is also slippery. Kavka argues that affect can shift between people, objects and situations when it "properly belongs elsewhere," and has a "loose and ever-transformable relation to both object and cause” (Kavka 2008, 30-31). An example can be taken from a Twitter update from Jeph Jacques, 5 the author of the webcomic Questionable Content (Jacques 2003). A reader told him they had been so upset at work over events within the comic that a concerned boss had asked if they were okay, and the only response they could think of to describe why they were crying was "two friends of mine broke up" (Jacques 2010). We can become downcast because of something fictional, and have that colour the rest of our day despite also feeling ridiculous 
about it: affect can have a powerful impact on our experiences even when we are aware of its influence and feel it to be irrational.

One of the reasons that affect is capable of escaping from a very contextual investment and travelling with us into other parts of our lives is because we are provided no affective insulation by the fact that we know we are engaging in fictional contexts. R.T. Allen and Grant Tavinor have asked how we can feel so strongly for characters we know to be fictional (Allen 1986, 66; Tavinor 2003, 2), and part of the answer is that we choose to be: we are invested in treating fictional characters as real, and so they feel real - and the affects and emotions we feel are real - even when we know intellectually the characters we feel them for are not. There is no compartmentalisation between our fictional relationships and our real ones, meaning that they can inform our day-to-day experience as much as any other relationship we have, 6 and the experience does not cease to be affectively powerful when we stop reading the text, watching the movie, or playing the game.

In order for this dimension of affect to be analytically relevant to our experiences of fiction and the way those experiences are shaped, we need to understand how and why we might sensibly 'feel responsible' for someone we know to be fictional - and the answer is, 'the same way we would feel responsible for anyone real.' Bernard Weiner engages with affective responsibility in the context of putting forward an attributional theory of motivation that relates thoughts and emotions to behaviour and social conduct. Weiner argues that assigning responsibility requires the perception of human or personal agency: a falling rock might damage a car but is not responsible for it, where a cat might be considered responsible for wrecking a couch - though comparatively less responsible than a child would be for causing the same damage (Weiner 1995, 6). If failure is caused by a lack of aptitude, then the cause is located within the person but cannot be controlled:

"In these instances, it is asserted that the person will not be judged as responsible for a negative event or a personal 
plight because accountability requires that the causes of these conditions can be wilfully changed. Responsibility, therefore, is intimately linked with freedom and choice." [Emphasis mine] (Weiner 1995, 7)

According to Weiner, anger communicates that someone 'should have' either done something or avoided it, thus failing in their responsibility, and that guilt and shame follow from perceiving yourself to be responsible (Weiner 1995, 18). In comparison, sympathy is generated when others are seen as not responsible for a condition they are suffering from. In all cases, the more important or personally relevant the context, the greater its affective intensity.

So, all that is required to 'feel responsible' for a fictional character is to be invested in them as if they were real, believe that their situation is not of their own making, and feel that you were capable of stopping it from happening. That last component is key: in books and films we can sympathise with characters and understand that key narrative misfortunes are not their fault, but there is no way for us to intervene - and we know that as we engage with the story.

The next section will explore the textual structure of videogames, and how the modes of engagement which set the experience of playing videogames apart from other forms of mediated storytelling are grounded in the exact traits that promote feelings of responsibility.

\section{EVERYTHING IS YOUR FAULT (OR SHOULD BE)}

When playing videogames, the hybrid of the player, hardware and game is part of the player's contextual world-of-concern, and the experience mediated by the hybrid functions because the player is invested in it. Following Latour's logic regarding how people operate within in hybrid networks (Latour 1999, 176-177, 179-180) means that agency - defined by Janet Murrary as “...the satisfying power to take meaningful action and see the results of our decisions and choices” (Murray 1998, 126) - becomes distributed across the network. The players of games are able to take meaningful action 
within games because the rest of the network works with them, enabling them to do so while simultaneously framing and restricting the forms of agency that are possible - a restriction that Gordon Calleja argues is central to ludic play (Calleja 2011, 148). It is important to note that the network can frame and restrict the decisions that are possible not just via the underlying 'rules' of the game, but via the fictional context that the player is invested in:

“Claims, such as Newman's and Aarseth's above, that Lara Croft's depiction in Tomb Raider as a human female matters less than what her body allows the player to do ignores the very fact that the player only considers 'walk', or 'run', or ‘jump' as viable options because Lara Croft is represented as a human being capable of such actions. Further, Lara Croft's representation as a human being suggests that the player should jump over the bottomless pit rather than fall into or float over it.” (Keogh 2014)

However, being part of a hybrid network does not simply afford the person engaging with it a negotiated agency when engaging with the fictional world-of-concern, it also has an immediate affective impact. The feeling of running into another car in Grand Theft Auto 4 (Rockstar North and Rockstar Toronto 2008) is different from actually being involved in a car accident, and different again from reading about or watching one in fiction (Veale 2010; Veale 2012a, 70).

The experience of videogames is personal as a result of hybrid engagement, in that it is all about you: the players of videogames are the ones who make progress through the hybrid text, and come to feel responsible for the outcomes of their decisions and actions in the process. Players7 are invested in the distinctive tenor of experience created by making meaningful decisions with sensible consequences within the space of the game. The structural elements that make such a dynamic possible are agency and coherence, which combine to make the player aware of a timeline of their own decisions in playing the game, and frame the experience as happening now. 
This section will explore the structural elements of videogames that create distinctive modes of engagement, and then argue that the experience of playing videogames is set apart from other forms of mediated storytelling by making the player consider their own future actions and decisions with affective weight, because they know they will feel responsible for whatever the outcome turns out to be.

The process of negotiating the underlying textual structure of videogames - its substrate, the structure which defines what a text is (Hayles 2002, 39) - requires choices on behalf of the player, framed by the hybrid the player is negotiating with. As a result of this basic mode of engagement for videogame hybrids, you have a negotiated agency - and any dynamic that understands your decisions have consequences strongly implies you are responsible for those results. In a simple example, incorrectly timing your jumps in Donkey Kong (Miyamoto 1981), results in Mario getting flattened by a rolling barrel. The dynamic that emphasizes consequences to choices made in negotiating game texts is why players often use the phrase 'I died,' to describe failure in games: their decision was key to the outcome, so they are responsible for the results. Perceptions of agency and responsibility are inherently linked.

However, agency in games is itself a source of critical tension,8 and it requires specific contexts in order to work. The example of jumping over the barrel in Donkey Kong functions because the consequences are sensible and predictable: get hit with a barrel and die, jump over it and survive. A consistent framework of decision and consequence allows the player to make meaningful decisions: if any elements become unpredictable then it is no longer entirely in the player's hands. Steven Poole uses the term structural incoherence to describe situations where consequences in games have weird results that are at odds with what the expected result of a situation would be (Poole 2000, 95). Something as simple as knocking a piece of stone into a river as you move past within a game space poses a good example; if the stone sinks with a splash, then that's a consequence that fits our expectations and reinforces our investment. In comparison, if the stone sits on the surface of the water like it would on a tiled floor, 
this underlines that we are engaging in an unreal, mediated space. As a result, it is harder to become invested in the space of the game as a real space, and to feel responsible for the results of your actions in that context.

Interestingly, designers have learned what a negative impact structural incoherence has on the player's experience of the game, and have worked to avoid it. Paying attention to the contextual details of the game's environment helps eliminate most of the problem: don't confront players with a chain-link fence if you want it to be an impassable barrier because anyone sufficiently motivated and ablebodied can scale one given time. If you want an impassable barrier, using a tall and featureless wooden fence that provides no handholds will work better because the player is less likely to think 'I should be able to climb that'.9 Essentially, since players are active components of the affective hybrid that makes up play, and since they seek to invest in an experience as if it were real, they are likely to accept contextually sensible reasons for their agency to be framed or restricted.

Half-Life 2 (Valve 2004) is full of physics puzzles that mostly avoid structural incoherence, including an item called a 'gravity gun' that allows you to levitate objects and throw them. The gravity-gun itself is obviously impossible, but is not perceived as 'incoherent' because the science-fiction context of Half-Life 2 provides justification for its function, and it is internally consistent. Players are shown how it works, and can then apply lateral-thinking to solve problems: the gravity-gun can be used as an impromptu weapon precisely because hurling a high-speed radiator, brick or saw-blade at an enemy gets the results you would expect.

When texts provide both agency and structural coherence (i.e. the outcomes of choices and actions are internally consistent and fit within the player's expectations when they made that decision), it reinforces a sense of responsibility that will underline the importance of future choices. Such a dynamic is a result of the modes of engagement common to engaging with game hybrids, and has 
affective consequences for play: when you know decisions you've made in the past mattered in the context of exploring the game, you assume that the outcomes of future choices you might make will be equally weighty. It's a feedback loop, but one that can be disrupted: if at any point you do not feel responsible for something that happens in the game, the experience is intensely frustrating. If we apply Weiner's ideas about attributed responsibility to videogames, people get angry when the parts of the hybrid outside of the player (i.e. the physical interface, software and hardware platform) are seen to be failing in their responsibility to be coherent systems and implement the framed decisions made by the player, usually due to a glitch or fault in the game itself, or poor game design. As soon as responsibility for problems is directed anywhere outside the player, the system falls apart by forcibly bringing the mediation presented by the hybrid to the player's attention. 10

Mass Effect (BioWare and Demiurge Studios 2007) is a good example where the different parts of the hybrid are not running in affective synch: the summaries of what you are choosing to say in conversation leave gaps between what you choose and what happens, meaning you are not making fully informed decisions. This often is not too serious a problem, but can result in situations where you choose to be rebellious and have problems with authority, only to find the game adding racist opinions that are now considered to be part of your protagonist's outlook on the world. Given that players are invested in the outcomes of the decisions they make in the game, being presented with outcomes you didn't choose and don't want to be responsible for limits the extent to which you're going to take future decisions seriously. In comparison, Dragon Age: Origins (BioWare and Edge of Reality 2009) does not share the problem: there can be situations where the hybrid limits the player's agency to choices that do not reflect their character's preferences, but every decision has the expected outcome rather than a concealed twist. As such, papering over the cracks with the player's investment in the contextual world-of-concern is easier than it is when the game concludes you really wanted to be racist. 
In comparison, if a player feels that they are responsible for their own failures within a 'fair' system, they will accept vast amounts of punishment. Iconic arcade games like Space Invaders (Taito 1978), Pac Man (Namco 1980) and Defender (Jarvis et al. 1980) were known for their difficulty, but were also known to be polished and fair in that the mistakes made by the player were theirs to own.11 In recent years there has been a resurgence of ruthless games that still present systems players can learn and improve at, such as Super Hexagon (Cavanagh 2012), Flappy Bird (Nguyen 2013) and examples that used the format for storytelling like Hotline Miami (Söderström and Wedin 2012) or Dark Souls (Miyazaki and From Software 2011). All these games share a common feature, in that failure is a common but brief setback: at the touch of a button (or inserted coin), the player is back in action still invested and intent on not repeating their mistake. It's possible for players to become angry at themselves, knowing precisely what they 'should have' done differently even as the mistake cost them their game. No matter how hard games are to successfully negotiate, if players believe that the barriers to their progress are their own mistakes, they keep coming back.

The modes of engagement associated with playing games also imply a direct relationship between the player's decisions and the timeframe of the experience: the game and its consequences are unfolding now "Not just in the sense that the viewer witnesses events now, but in the sense that the events are happening now, and that what comes next is not yet determined," (Juul 2001).12,13 Barry Atkins picks up on this idea when he argues that the distinction between the audience who watch a game being played and the person playing is that the audience watches the screen now, when the player is “...invested in the screen as a nexus of possible decisions and possible outcomes, meaning that they are oriented towards the future” (Atkins 2006, 134-135, 137). Gordon Calleja uses the concept of 'future orientation' to explore ergodic literature, as introduced by Espen J. Aarseth (Aarseth 1997). For Aarseth, ergodic engagement is when a text is negotiated through "processes of choice, discernment and decision-making," (Veale 2012a, 23), but Calleja extends the idea further by including moments 
where the player is ready to make a decision in response to events in the game:

"In Red Orchestra (Tripwire Interactive, 2006), a firstperson shooter game, for example, a player is lying on the floor of a three-story ruined building, covering a street with a sniper rifle. There are no enemies in sight, but the sniper expects them to emerge in the near future as the street leads to one of the main game objectives on the map. Long minutes of inactivity result from such a wait, yet the sniper's job is often defined by this sort of patient waiting. Although there is no direct input on behalf of the player, the readiness to act requires her to stay alert. At any second someone might emerge around that street corner, and the sniper must be ready to deal with him, or the fruits of her labour will go to waste.” (Calleja 2011, 42)

The mode of engagement that distinguishes playing videogames means the player is aware of a timeline of choices and consequences stretching behind them into the past, the immediate choices confronting them now, and the options on their horizon.14 Players can find themselves considering potential choices and their outcomes with weight and gravitas, all because they will feel responsible for the consequences of whatever they choose.

When someone is affectively invested in the experience of playing a game, being and feeling responsible for other characters is a significant part of forming affective relationships with them that matter to you, and the fact that it matters is self-reinforcing. A feedback-loop forms because the associations we have built up with these characters - and our affective investment in them as if they were real people - underlines the sense of responsibility we bear in mind when making decisions. A sense of agency leads to players treating the world of the game as a legitimate, living space, and that affective investment in a living space is folded into treating the relationships there as legitimate relationships. The cycle completes when these relationships then reinforce the impression of the game- 
world as a legitimate environment with internally consistent causeand-effect consequences to actions, and then starts again.

As an example of how people can invest in fictional characters, Alec Meer recounts waking up thinking of the name 'Anatoly Kolotov,' but being unable to recall where it was from (Meer 2009). He eventually remembered that it was a randomly-generated name for a character in X-COM: Enemy Unknown (Mythos Games and MicroProse 1994), a game he had played years previously:

"He'd been with me since the very start of the game.... One day, Anatoly Kolotov died. I don't remember how, but I remember the shock. I remember feeling absolutely hopeless - how could I possibly save the world without Anatoly's help? (...) I do know I reloaded a savegame. It was not yet Anatoly Kolotov's time to die, I reasoned. Nonetheless, the trauma of losing a character that felt so thoroughly mine, one I'd nurtured and developed rather than simply witnessed trot through a game's scripts, was formative.... This was someone I'd personally invested in, ripped brutally away from me.” (Meer 2009)

Since players are affectively invested in both their capacity to act upon the world of the game and the other characters sharing that context, they are also invested in how their actions affect those characters. Weiner's argument is that humans frame perceptions of responsibility around the degree to which the person committing an action or making a decision has agency, and that the more important and personally relevant the context, the greater the affective intensity is. Videogame players are actively invested in seeing themselves as agents within the games they play, and their decisions have meaningful impact on other characters around them - and all of this happens within a contextual world-of-concern that they find personally relevant.

As a result, players are cued to be critical of the outcomes of their own actions: they feel guilty and responsible when something negative 
happens as a result of something they could have avoided; anger for occasions where the blame can be directed outwards, such as where the failure was beyond the player's control due to a glitch; and sympathy for characters who suffer negative consequences and are not responsible for causing them, since by definition it's the player who has agency (as framed by the hybrid of play). As part of the same dynamic, players can feel entirely legitimate pride at positive outcomes they achieve for themselves and other characters within the game, all of which also reinforces their investment. There is very little ability to defer responsibility for the consequences of your decisions, regardless of whether they are positive or negative: even if the consequences are unintentional, there can be no argument that they are not your decisions because your decisions and actions 15 are the only ones reflected in the space of the game.16 The modes of engagement that distinguish the experience of videogame play are open to the experience of what Christy Dena refers to as 'eureka discourse' in the context of Alternate Reality Games - a 'language of discovery' where the person negotiating the text experiences 'aporias and epiphanies' directly, since they are responsible for overcoming obstacles 'themselves' (Aarseth 1997, p. 91-92 ; Dena 2008, p. 53).17

The person playing a game text has a negotiated agency within the hybrid established between them and the technological platform running the game. The modes of engagement involved in negotiating that hybrid text present the player with negotiated agency due to the choices provided to them within a contextual world-of-concern they are affectively invested in. The player's perception of their own agency suggests that they are responsible for the outcome of decisions made within the world-of-concern, particularly since the player is affectively invested in the idea of being an active agent within that context.

The next section explores a series of case-studies exploring specific ways that the modes of engagement common to engaging with videogame hybrids lead to perceptions of responsibility, and how these make the affective experiences of the games in question distinctive. 


\section{WHAT MAKES THE EXPERIENCE OF GAMES DISTINCTIVE}

The modes of engagement common to videogame play mean that there is less 'affective mediation' than what is experienced through other forms of storytelling because you are the one who responds affectively to events, not the protagonist of a novel or film who the audience hopefully sympathises with (Veale 2011, p. 44).18 When players of Bioshock (2K Boston 2007) reach the 'Would You Kindly' revelation, they are not engaging with a fictional character who feels betrayed, they feel betrayed themselves - all the decisions they've felt responsible for cast in a terrible new light.19 Likewise, games like Bastion (Supergiant Games 2011) and Shadow of the Colossus (Ueda and Team Ico 2005) create situations where the player might simultaneously feel pride in their accomplishment and growing doubt that they are doing the right thing, which can lead to an unfocused dread of what their progress might result in.

John Walker has written about an occasion where he set out with the specific task of selecting every 'evil' choice within Star Wars: Knights of the Old Republic (BioWare 2003) to see what happened, only to become so guilty and uncomfortable at the outcomes of his decisions that he had difficulty finishing the game (Walker 2009a ; Walker 2009b ; Walker 2009c ; Veale 2011, p. 46).

"Dia had attacked her boss with a spear, leaving him with a scar, and the boss wanted her dead. The Hutt hinted that perhaps Dia wasn't quite so guilty as the story made out, and the extent of this became abundantly clear when I found her boss in a strip club. He confessed that while drunk he had attempted to force himself upon her, and she had struck out to prevent him. It was an attempted rape. The conversation options were there - I could take him out right now. I could destroy this horrendous man, who was having a woman he'd tried to sexually assault murdered, because she had beaten him. 
The feeling when selecting the option saying I agreed with him, and she was getting what she deserved, was just revulsion. Sure, this is a game. Sure, no one was really getting hurt. But bloody hell, there are some things it's just never okay to do.” (Walker 2009a, p. 3)

The same lack of affective mediation that can make players genuinely uncomfortable with themselves can make the experience of storytelling situations affectively powerful. Gone Home (The Fullbright Company 2013) places the player in the same context as the protagonist both narratively and affectively: you are in an unfamiliar environment during a storm, trying to piece together exactly what happened and find out where everyone's gone.

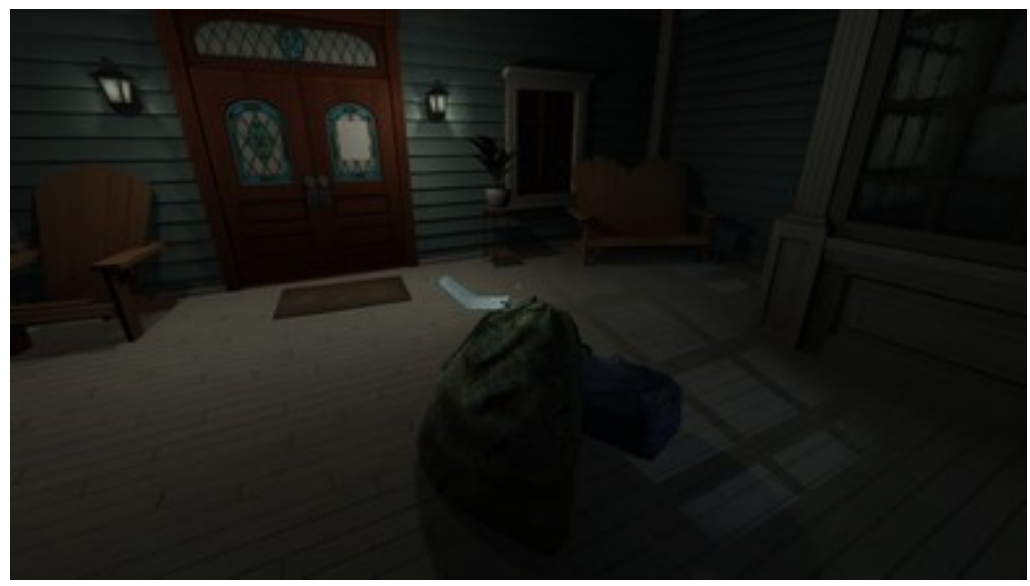

Figure 1: The first problem of Gone Home

Gone Home frames you as a young woman who has returned from a year overseas on an earlier flight than planned, and who has reached her family's new home at 1:00 AM in a torrential storm. Except, nobody is here to greet you, and there's a note on the locked front door from your sister saying that she's gone and not to look for her. The mystery is immediate. Plus, there's nowhere else you can go, and you have no tools at your disposal - so the only option is to explore the porch and try to figure out what to do next. As you explore a cupboard (potentially out of idle curiosity), you discover a collection 
of Christmas ornaments - including a festively-attired plaster duck. When the player picks it up to examine it further, you find a spare key underneath. The discovery is a great example of both Dena's eureka discourse (Dena 2008, p. 53) and the mode of engagement that the game privileges: you're poking around without clear direction and then in response to your exploring there's a surprise key, opening up access to the darkened foyer of an unfamiliar house as rain batters on the windows. At that point, you have no idea what's going on, so the natural impulse is to explore an environment as unfamiliar to the protagonist as it is to the player themselves, trying to piece together the mystery of whatever happened over the last few days - and then as you start connecting disparate threads, the mystery of the last year of your family's lives that you missed.

The game very carefully manages the agency provided to the player and eliminates structural incoherence so that your capacity to act equally matches the protagonist's context: if you want to dig through rubbish bins looking for notes, you can. You can do the same things as you would be able to do in an actual house in the same situation, like opening drawers and cupboards, even if doing so has no impact on advancing the story.20 The exceptions to this rule are intelligently managed: you're in your family's new home and you're not sure what's going on, so kicking down doors seems like a bad idea. Likewise, sure you can't open the garage door, but what with the storm outside why would you want to? Returning to the chain-link fence example discussed from Half-Life 2, Gone Home is grounded in internally consistent reasoning for barriers to progress and boundaries in the game, making it a very structurally coherent experience. Essentially, the player's agency is framed and restricted within the hybrid in contextual ways that they are affectively invested in accepting as 'real,' so a restricted agency can still reinforce their engagement in the space as a legitimate, lived space.

The game reflects what you do: the experience can be one of cautiously building a picture of a threatening mystery, or of running around in a panic turning on all the lights before trying to figure out what's going on. It's possible to have the awkward and startling 
experience of stumbling onto more than one family member's hidden porn in the course of your amateur sleuthing. In what I consider to be a brave design decision, there is no attempt to artificially force the protagonist through the story: I know someone who accidentally stumbled onto the secret area under the stairs in the first room almost immediately and then followed directions to the attic, finishing the game in minutes. She, like the protagonist, had missed out on most of the substance of the background story, but came away feeling that although she did not have most of the answers, everything was going to be okay. Even in what could have been a narrative-breaking scenario, Gone Home was a satisfying and internally consistent experience that reflected the player's choices and discoveries in exploring the space of the game and its story, and which framed the player and the protagonist in the same affective position.

When games feature branching narrative developments that reflect decisions made by the player, games have the capacity to make them so organic that they can be invisible. An example can be taken from a conversation between Kieron Gillen and John Walker where neither of them realised that events in Deus Ex (Ion Storm 2000) could play out differently than they had individually experienced, until they compared notes:

"Kieron and I... were chatting about various moments, sharing thoughts, and then I said, 'Wasn't it awful when your brother died?'

Kieron replied, 'My brother didn’t die?’” (Walker 2009d)

Noticing that a game is presenting a forking path is something that may not damage a player's engagement or investment in the space, but it is a noticeable part of the experience. If you don't notice such a fork, then you are instead focusing on your investment in what seems to be an entirely reasonable, organic extension of the choices you have made, and where you are paying more attention to the decisions you are responsible for than the alternatives. Gillen 
and Walker elaborate on their own experiences, and the power those experiences held, in some depth:

"Of course it turns out whether you save [the brother] or not, you still travel next to Hong Kong. I went there to recover a chip from his body. Kieron went there to meet his brother. I broke the news of [the brother's] death to his girlfriend. Kieron went to see his girlfriend for other reasons. We both played exactly the same game, playing through exactly the same levels, but our motivations were dramatically different. Neither of us could perceive a game in which we would go to those places for any reason other than those we had at the time, creating the sense of something unique to our decisions and experiences.” (Walker 2009d)

In comparison, some games emphasise an awareness of the experiences you are choosing not to have. Every option that you are presented with in Kentucky Route Zero (Cardboard Computer 2013) exists to be an evocative hook that might illuminate more of what you understand about the world and its characters, but the game uses the fact you have to choose to shape the affective experience of playing.

Kentucky Route Zero is a game grounded in magical-realism that begins with a truck driver named Conroy trying to make a delivery with his dog, and a seemingly mundane context gradually branches into a quest for a mysterious underground highway. It is an experience rich with textured meaning and layers of imagery, and is very open to being explored for new depths. It's possible to just drive around the back roads of Kentucky and explore the brief text descriptions associated with evocative locations, or events that unfold as you explore. 


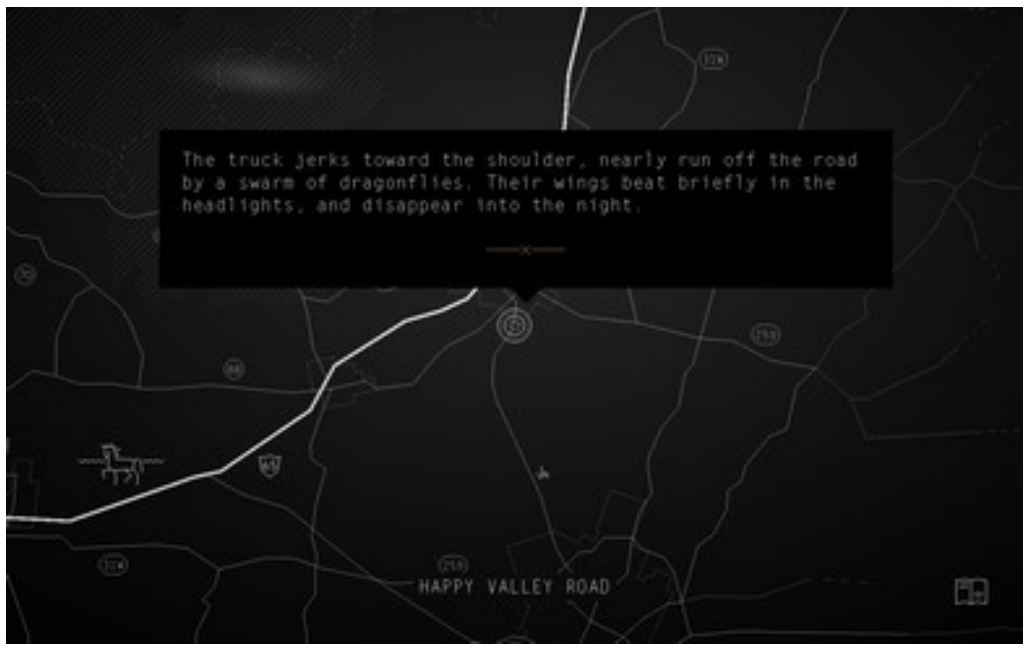

Figure 2: Poetry on the road

Throughout the game, you make decisions as to what characters say in conversation, and the game carefully arranges all of the options to be enticing hooks that will illuminate new parts of the world and you can only ever choose one option from each list. Kentucky Route Zero even sometimes presents mutually exclusive things for characters to remember and recount, meaning that when you choose something you are constructing the histories of the characters as you go. For every option you take there are several you do not, and the pangs of affective loss for things we can never explore or learn about are one of the striking elements of the experience that have stayed with me, and which contribute to the wry tones of the game. 


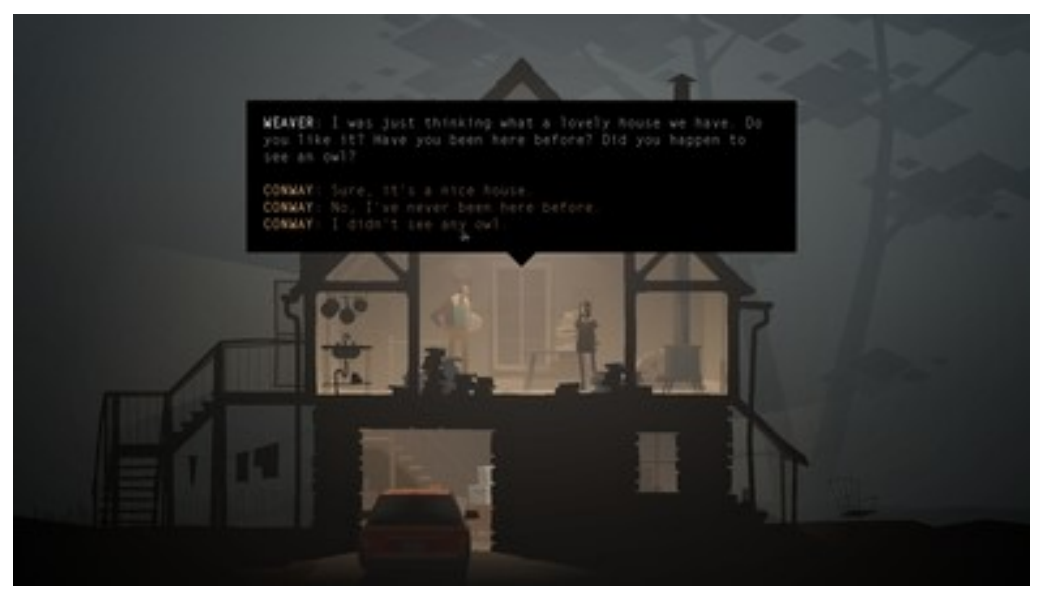

Figure 3: A choice you can't return to in Kentucky Route Zero

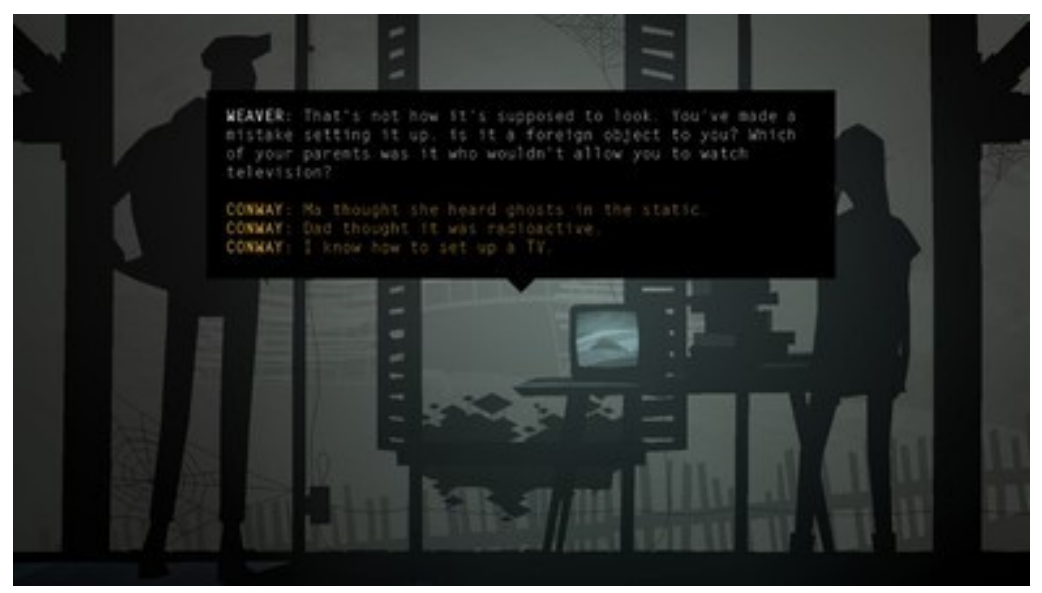

Figure 4: Do you want to be defensive, or learn more about radiation or ghosts?

Given that failure in games frequently involves 'death,' it's unsurprising that some extremely evocative affective experiences are associated with dying. One of my own experiences of death in games was memorable precisely because of how horribly guilty and responsible I felt for it, despite the fact that what I felt guilty for lay outside the boundaries of the text itself: my affective response existed in a world-of-concern that extended outside the hybrid of playing the game. In Portal 2 (Valve 2011), the viewpoint-character 
and protagonist is a young woman named Chell who has to escape from an underground facility called Aperture Science that was built for the express purpose of unregulated experimentation, and which has since gone rogue. For part of the game, you hear regular recorded conversations from Cave Johnson, the man who built Aperture Science, such as where he describes the first of a series of gels that alter physics in fascinating ways - and which are all horrifyingly dangerous. As Cave Johnson says:

"Oh, in case you get covered in that Repulsion Gel, here's some advice the lab boys gave me: [sound of rustling pages] 'Do not get covered in the Repulsion Gel.' We haven't entirely nailed down what element it is yet, but I'll tell you this: It's a lively one, and it does not like the human skeleton.” (Valve 2011)

I still remember the absolute chill that went down my spine when I was careless and became coated in blue goo. My instinctive assumption was that I'd 'died' and the game would automatically reload the level so I could try again... but instead nothing happened. There was no in-game acknowledgement that I'd just ruined poor Chell's skeleton. I restored the game anyway, specifically because I was unwilling to accept the idea that Chell's seemingly inevitable demise would be my fault - only for it to happen again. I remember how sorry I felt. Sorry because I could not spare Chell the fate that I'd doomed her to, and sorry because I didn't have the skill to prevent it from happening. Later in the game, players are presented with a different gel that has notably already killed Cave Johnson. I felt utterly mortified when I became coated in murderous fluid again because I had made the situation worse: Chell had already been doomed because of me, but now her death was going to be more painful. I went back and tried again, but could not do it. To this day I am unsure whether finishing the game without getting exposed is even possible, but I experienced it as a personal failure that cast a (thematically appropriate) shadow across the rest of the game.

Such an experience of ongoing remorse would not be possible 
without the modes of engagement that function within the hybrid and the world-of-concern that surrounds it. Being the person responsible for the outcome of thousands of small decisions allowed for within the hybrid I formed with Portal 2 meant it was natural to understand myself as responsible for events that 'will happen' outside of the scope of the text itself.

\section{CONCLUSION}

In this paper I have argued that the underlying substrate of a text is not neutral, and seemingly trivial shifts can have dramatic consequences for our experiences of storytelling. The substrate makes up the text, and can be understood as the structure which defines what a text is. That first layer is what we engage with when we negotiate a text. Different shapes of substrate require different processes of the person negotiating the text, and these modes of engagement in turn shape the experience. We can analyse both how the underlying textual substrate shapes our modes of engagement, and how those modes of engagement have an impact on our experience of the story being mediated.

The experience of videogames is set apart from other forms of storytelling media because the person playing the game feels responsible for events within the fictional world. This happens as a natural outgrowth of a mode of engagement where people have agency and need to make decisions and take actions in order to proceed through the text, in a context that the player is affectively invested in, and which is personally relevant to both the player and their situation. A perception of responsibility grows out of that agency, since their decisions have a meaningful impact on a world and characters that the player is already invested in treating as if they were real.

Although agency is common to all videogame texts, we can analyse how the game frames that agency, the consequences that grow out of it, and the perception of responsibility felt by the player. We can examine what effect the game's structure has on the modes of 
engagement available to the player, and how those modes of engagement shape the player's experience. We can explore how the responsibility felt by the player is folded back into the game and used to reinforce their investment in the experience, such as considering how the game refers back to earlier decisions the player has made. This approach allows for a toolset we can apply to understanding how videogames shape storytelling experiences that are distinct from other forms of mediated storytelling.

However, feeling responsibility in a fictional context is not only relevant to videogame experiences. Such a perception of responsibility is an outgrowth of affective investment within a particular mode of engagement, and it is possible to duplicate elements of that mode of engagement using more traditional media forms. I argue that textual modes of engagement are as important to our definition and understanding of different forms of mediated storytelling as the underlying textual substrate is. Exploring modes of engagement is a line of enquiry that can lead to unexpected places. For example, a pragmatic element of reading a book is that we know how far through the book we are as we read, because of an awareness - no matter how subconscious - of how many pages there are to go. If a climactic battle is still going on with only a handful of pages remaining, I have wondered how the author can finish the story in the space left. Moving the same novel from a printed context to a digital one can eliminate that information21 and changes our mode of engagement.

Even though the territory covered in this article has been focused solely on exploring what sets apart the experience of videogame texts, I suggest that understanding how different modes of engagement shape our experiences of fiction will be helpful not just for the analysis of storytelling in the context of videogames and other new media, but for understanding how we have already been telling stories for a very long time.

\section{ACKNOWLEDGMENTS}


Many thanks to Dr. Radha O’Meara of the University of Melbourne, Brendan Keogh of RMIT University, and Dr. Hannah Gerrard of Massey University in New Zealand for assistance in refining this article. Thanks also to Dr. Thomas Apperley of the University of New South Wales for stopping me from getting lost in Melbourne in the wee small hours of 2014.

\section{ENDNOTES}

1 Although the scope of this article is focused on how the textual structures of videogames and the processes we as players go through to engage with them shape their storytelling experiences, such an analytical approach has broader relevance and is not limited to exploring storytelling in a digital context.

2 Brian Massumi frames affect as an unqualified intensity that is "resistant to critique" (Massumi 2002, 27-28), which has raised concerns that affect is not a useful term for analysis. This concern can be seen in dialogues between Massumi and Lawrence Grossberg, where Massumi argues that Grossberg moves away from positioning affect as unstructured and unformed precisely to avoid accusations that doing so means affect cannot be analysed (Massumi 2002, 260). Massumi instead argues that because form and structure are not the only analytical frameworks that can be applied to affect, being unformed and unstructured are not barriers to its study - and that Grossberg is falling into terminological slippage that equates 'affect' directly with 'emotion' in an attempt to avoid a situation that is not a relevant concern (260).

3 I use 'they' as a singular gender-neutral pronoun, and use 'their' as a less disruptive use of a possessive than 'his/hers.'

4 I use 'you' throughout this article as a way of framing an experience in general terms, on the grounds that it is simple and direct. It also is a mode of address that Brendan Keogh argues is "common to videogames and the discourses surrounding them," and which "draws 
attention to the player-and-game hybrid" by collapsing together the player and the character of the game” (Keogh 2014).

5 http://twitter.com/jephjacques/status/5397351535480832 November 19th 2010, 12:10 PM (Jacques 2010)

6 Yet we are never unaware of their status as fiction.

7 This article will refer to the people who play games as 'players,' although doing so places emphasis on the human element of the hybrid, because I cannot think of elegant language to use as a replacement. Whenever I use the term, I am referring to the person experiencing a hybrid network.

8 Steven Poole has gone so far as to argue that any perception of agency is illusory, and players are merely rats running the maze set up by the game's designers (Poole 2000, 106-107). My counterargument is that players experience playing the game as if the decisions are theirs because they are invested in being agents within the hybrid context, so whether or not agency is illusory is irrelevant to its impact on the experience of play.

9 Context matters, however, even in cases like this: there is a strong tradition in point-and-click adventure games that one stays on posted paths, so rope fences are likely to be read as impassable by players. Cases where the solution to a puzzle is to break with tradition and cut the rope are frustrating as a result.

10 Affective responsibility is also relevant to multiplayer game experiences, and is a fundamental element of how and why players respond so strongly (and frequently, badly) to losing (Tassi 2014). When a player knows that they played as well as they possibly could but still lost decisively, their affective frustration is grounded in helplessness. The frustration is made worse if the loss is seen to be caused by mistakes made by team-mates, or glitches in the game, but players are still likely to lash out or carry their tension from the game out into the rest of their lives even if it was simply that they were outplayed by more-practiced opposition. The same dynamic 
can be seen in scenarios where players feel actively bad for their opposition who are losing because several players have disconnected, gone offline, or some combination of factors beyond their control.

11 This also emphasises that affective engagement and a perception of responsibility in games does not require detailed graphics, it just requires that they offer players the agency and coherent design that will create fertile ground to invest themselves in.

12 One side effect is that games are much less likely than films to use ellipses to stop the player being exposed to 'dead time' where little is happening or the action is repetitive - even if it might be preferable (King and Krzywinska 2002, 144; Juul 2004, 138). Conversely, videogames also introduce a new form of 'dead time' with loading screens, which create a dynamic where the player is engaged in the world of the game but cannot take action until the game is ready for them - essentially putting the player themselves 'on pause.' The more frequently such pauses happen and the more disruptive they are to the context of play, the more loading screens are a barrier to player engagement. Videogame designers have become adept at concealing loading screens during other action (such as using elevators or other forms of automated travel), rather than having them strike whenever the player opened a door - or sometimes randomly in the middle of rooms.

13 Jason Wilson presents a persuasive critique of Juul's argument in Gameplay and the Aesthetics of Intimacy (Wilson 2007). I include reference to Juul's argument here because it provides a starting point for the consideration of how players relate to choices in games, rather than an endorsement of Juul's argument regarding the formal characteristics of games.

14 And, as described by Calleja, this is true of games that don't specifically include branching decisions at the levels of narrative or character, even ones as simple as Pong (Alcorn 1972), Space Invaders or Tetris (Pajitnov and Pokhilko 1984) 
1. Within the context of hybrid engagement.

16 At least, for single player games.

17 The simplest example to explain the experience of "eureka discourse" in practice is the freely available browser game Frog Fractions (Crawford and Twinbeard Studios 2012), which is available at: http://twinbeardstudios.com/frog-fractions. The game is an exemplar of the kind of experience that makes videogames distinctive, and is grounded in moments of personal discovery. Unfortunately, any attempt to explain why will ruin the effect something true of all eureka discourse - so playing the game yourselves is the best option for learning more.

18 It is important to note that this is not an argument that videogames and other computerised forms of storytelling are 'better,' 'more immersive' or 'more immediate' than traditional modes of storytelling, like cinema, prose, or comics. The experience of playing videogames is a fundamentally different mode of experiencing fiction, and figuring out how and why that is will be helpful in understanding how our engagement shapes storytelling experiences - regardless of what form of media a given piece of fiction is to be found in.

19 If you are unfamiliar with the reference, the summary is that throughout Bioshock, a friendly presence in the hostile undersea city of Rapture discusses with you the problems you're both facing, and how you can help set things right. Being Irish, the man commonly uses the phrase "Would you kindly...?" as a way of setting up his requests. Later in the game, you discover your character has false memories, and has been conditioned to unthinkingly obey any instruction delivered after the statement "Would you kindly." Thus, all the player's own decisions and actions are called into question, and things you have taken responsibility for turn out to have been manipulated by a puppet-master all along.

20 Some productive links can be made here between this article, 
Jenkins' ideas regarding narrative architecture (Jenkins 2004), Wilson's 'gamic mise-en-scene' (Wilson 2007), and Ash's explorations of how game design creates environments designed to manipulate affect (Ash 2010; Ash 2012), since we appear to be approaching the same territory from different directions.

21 Depending on whether the e-reader software contextualises where in the book you are as you read.

\section{BIBLIOGRAPHY}

2K Boston. Bioshock [PC]. 2K Games, 2007. Played January 2009.

Aarseth, E. Cybertext: Perspectives on Ergodic Literature. Baltimore, Md.: Johns Hopkins University Press, 1997.

Alcorn, A. Pong. Atari Inc, 1972.

Allen, R. T. “The Reality of Responses to Fiction.” British Journal of Aesthetics vol. 26, no. 1 (1986): 64-68.

Ash, J. "Architectures of Affect: Anticipating and Manipulating the Event in Processes of Videogame Design and Testing." Environment and Planning D: Society and Space vol. 28, no. 4 (2010): 653-71.

Ash, J. "Attention, Videogames and the Retentional Economies of Affective Amplification.” Theory, Culture \& Society, November (2012), 1-24.

Ash, J. "Technologies of Captivation Videogames and the Attunement of Affect.” Body \& Society vol. 19, no. 1 (2013): 27-51.

Atkins, B. "What Are We Really Looking At?: The FutureOrientation of Video Game Play." Games and Culture vol. 1, no. 2 (2006): 127-40. http://gac.sagepub.com/content/1/2/127.

BioWare. Star Wars: Knights of the Old Republic [PC]. LucasArts, 2003. Not played by author. 
BioWare, and Edge of Reality. Dragon Age: Origins [PS3]. Electronic Arts, 2009. Played April 2015.

BioWare, and Demiurge Studios. Mass Effect [PC]. Electronic Arts, 2007. Played September 2012.

Calleja, G. In-Game: From Immersion to Incorporation. Cambridge, MA: MIT Press, 2011.

Cardboard Computer. Kentucky Route Zero [PC]. Cardboard Computer, 2013. Played March 2014.

Cavanagh, T. Super Hexagon [PC]. 2012. Played January 2013.

Crawford, J, and Twinbeard Studios. Frog Fractions [PC]. 2012. Played August 2014.

Danielewski, M. Z. House of Leaves. New York: Pantheon Books, 2000.

Dena, C. "Emerging Participatory Culture Practices." Convergence: The International Journal of Research into New Media Technologies vol. 14, no. 1 (2008): 41-57.

Fullbright Company, The. Gone Home [PC]. The Fullbright Company, 2013. Played April 2014.

Giddings, S. "Playing with Nonhumans: Digital Games as Technocultural Form.” In Worlds in Play: International Perspectives on Digital Games Research. New York: Peter Lang, 2007.

Grossberg, L. Dancing in Spite of Myself: Essays on Popular Culture. Durham, NC: Duke University Press, 1997.

Hayles, N. K. How We Became Posthuman: Virtual Bodies in Cybernetics, Literature and Informatics. Chicago, Illinois: University of Chicago Press, 1999.

Hayles, N. K. Writing Machines. Cambridge, MA: MIT Press, 2002. 
Ion Storm. Deus Ex [PC]. Eidos Interactive, 2000. Played October 2012.

Jacques, J. “Twitter Update”. 01 December 2010. http://twitter.com/ jephjacques/status/5397351535480832.

Jacques, J. Questionable Content. 2003. 04 December 2010. http://www.questionablecontent.net/.

Jarvis, E., L. DeMar, and S. Dicker. Defender. Williams Electronics, 1980.

Jenkins, H. “Game Design as Narrative Architecture.” In First Person: New Media as Story, Performance, and Game> Edited by N. Wardrip-Fruin and P. Harrigan, pp. 118-30. Cambridge, MA: MIT Press, 2004.

Juul, J. “Games Telling Stories?” Game Studies vol. 1, no. 1 (2001). http://www.gamestudies.org/0101/juul-gts/.

Juul, J. "Introduction to Game Time.” First Person: New Media as Story, Performance, and Game. Edited by N. Wardrip-Fruin and P. Harrigan, pp. 131-142. Cambridge, MA: MIT Press, 2004.

Kavka, M. Reality Television, Affect and Intimacy. Basingstoke [England]; New York: Palgrave Macmillan, 2008.

Keogh, B. "Here’s Looking At You: Re-Examining the Relationship of Player, Character, and Game.” Critical Damage, November (2010). http://critdamage.blogspot.co.nz/2010/11/heres-looking-atyou-reexamining.html.

Keogh, B. "Across Worlds and Bodies: Criticism in the Age of Video Games.” Journal of Games Criticism vol. 1 no. 1 (2014). http://gamescriticism.org/articles/keogh-1-1.

King, G., and T. Krzywinska. “Computer Games/Cinema/Interfaces.” 
Computer Games and Digital Cultures Conference: 2002. Edited by F. Mäyrä. Tampere University Press.

Latour, B. "A Collective of Humans and Nonhumans." In Pandora's Hope: Essays on the Reality of Science Studies, pp. 174-215. Cambridge, MA: Harvard University Press, 1999.

Massumi, B. Parables for the Virtual: Movement, Affect, Sensation. Durham, NC: Duke University Press, 2002.

Meer, A. “Gaming Made Me, \#2 - Alec’s Meeriad Influences.” Rock, Paper, Shotgun (2009). http://www.rockpapershotgun.com/2009/07/ 07/gaming-made-me-2-alecs-meeriad-influences/.

Miyamoto, S. Donkey Kong. Nintendo, 1981.

Miyazaki, H, and From Software. Dark Souls [PC]. Namco Bandai Games, 2011. Not played by author.

Murray, J. Hamlet on the Holodeck: The Future of Narrative in Cyberspace. Cambridge, MA: MIT Press, 1998.

Mythos Games, and MicroProse. UFO: Enemy Unknown [PC]. MicroProse, 1994. Played February 2012.

Namco. Pac-Man [PC]. Midway \& Namco, 1980.

Nguyen, D. Flappy Bird [PC]. GEARS Studio, 2013. Not played by author.

Nyre, L. “What Happens When I Turn on the TV Set?” Westminster Papers in Communication and Culture vol. 4, no. 2 (2007): 24-35 http://www.wmin.ac.uk/mad/pdf/WPCC-Vol4-No2-Lars_Nyre.pdf.

Pajitnov, A., and V. Pokhilko. Tetris [PC]. 1984.

Poole, S. Trigger Happy: Videogames and the Entertainment Revolution. New York: Arcade Publishing, 2000. 
Rockstar North, and Rockstar Toronto. Grand Theft Auto 4. Rockstar Games, 2008. Not played by author.

Shaw, I., G. Ronald, and B. Warf. "Worlds of Affect: Virtual Geographies of Video Games.” Environment and Planning. A vol. 41 no. 6 (2009): 1332.

Söderström, J., and D. Wedin. Hotline Miami [PC]. Devolver Digital, 2012. Played March 2013.

Supergiant Games. Bastion [PC]. Warner Bros. Interactive Entertainment, 2011. Played July 2014.

Taito. Space Invaders [PC]. Taito \& Midway, 1978.

Tavinor, G. "Fiction and the Emotions.” Doctor of Philosophy Thesis. University of Auckland, 2003. http://hdl.handle.net/2292/340.

Ueda, F., and Team Ico. Shadow of the Colossus [PS2]. Sony Computer Entertainment, 2005. Played August 2010.

Valve. Half-Life 2 [PC].Valve Corporation \& Sierra Entertainment, 2004. Played May 2014.

Valve. Portal 2 [PC]. Valve Corporation, 2011. Played March 2012.

Valve. Team Fortress 2 [PC]. Valve Corporation, 2007. Played December 2012.

Veale, K. "Comparing Stories: How Textual Structure Shapes Affective Experience in New Media.” University of Auckland, 2012a. http://hdl.handle.net/2292/10347.

Veale, K. “'Interactive Cinema' Is an Oxymoron, but May Not Always Be.” Game Studies vol. 12, no. 1 (2012b). http:/gamestudies.org/1201/articles/veale.

Veale, K. "Making Science-Fiction Personal: Videogames and InterAffective Storytelling." The Projected and the Prophetic: Humanity 
in Cyberculture, Cyberspace \& Science Fiction 'Critical Issues' Vol. 176 (2011): 41-49. https://www.interdisciplinarypress.net/my-cart/ ebooks/ethos-and-modern-life/the-projected-and-prophetic.

Veale, K. “The Amnotic Sac - Intersubjectivity and Affect in Computer Games.” University of Auckland, 2005. http://hdl.handle.net/2292/2867.

Walker, J. "Bastard of the Old Republic - Part 1." Eurogamer (2009a). http://www.eurogamer.net/articles/bastard-of-the-oldrepublic-article.

Walker, J. "Bastard of the Old Republic - Part 2." Eurogamer (2009b). http://www.eurogamer.net/articles/bastard-of-the-oldrepublic-article_2.

Walker, J. "Bastard of the Old Republic - Part 3." Eurogamer (2009c). http://www.eurogamer.net/articles/bastard-of-the-oldrepublic-part3.

Walker, J. “The Big Quest(Ion).” Rock, Paper, Shotgun (2009d). http://www.rockpapershotgun.com/2009/09/01/the-big-question/.

Weiner, B. Judgments of Responsibility: A Foundation for a Theory of Social Conduct. New York: Guilford Press, 1995.

Wilson, J. "Gameplay and the Aesthetics of Intimacy." Griffith University, 2007. http://spooner.beds.ac.uk/nmrg/wp-content/ uploads/2008/04/jason-wilson-phd.pdf. 